\title{
Remarks on 'Coupled coincidence point results for a generalized compatible pair with applications'
}

\author{
İnci M Erhan', Erdal Karapınar1,2, Antonio-Francisco Roldán-López-de-Hierro ${ }^{3}$ and Naseer Shahzad4*
}

"Correspondence:

nshahzad@kau.edu.sa

${ }^{4}$ Department of Mathematics, King

Abdulaziz University, P.O. Box 80203

Jeddah, 21589, Saudi Arabia

Full list of author information is

available at the end of the article

\begin{abstract}
Very recently, Hussain et al. (Fixed Point Theory Appl. 2014:62, 2014) announced the existence and uniqueness of some coupled coincidence point. In this short note we remark that the announced results can be derived from the coincidence point results in the literature.
\end{abstract}

MSC: $47 \mathrm{H} 10 ; 54 \mathrm{H} 25$

Keywords: fixed point; coupled coincidence point; ordered metric space

\section{Introduction}

Recently, a number of studies related to fixed points, coupled fixed points and coupled coincidence points of maps defined via auxiliary functions have appeared in the literature. In particular, the so-called weak $\varphi$-contractions, contractions defined by means of altering distance functions, $\alpha-\psi$-type contractions have been a subject of considerable interest. Studies of this type aim to generalize and improve contractive condition on the maps (see, e.g., $[1-15])$.

A great deal of these studies investigate contractions on partially ordered metric spaces because of their applicability to initial value problems defined by differential or integral equations. This is the case of the following result.

Theorem 1.1 (Hussain et al. [16], Theorem 15) Let $(X, \preceq)$ be a partially ordered set such that there exists a complete metric d on $X$. Assume that $F, G: X \times X \rightarrow X$ are two generalized compatible mappings such that $F$ is $G$-increasing with respect to $\preceq, G$ is continuous and has the mixed monotone property, and there exist two elements $x_{0}, y_{0} \in X$ such that

$$
G\left(x_{0}, y_{0}\right) \preceq F\left(x_{0}, y_{0}\right) \quad \text { and } \quad G\left(y_{0}, x_{0}\right) \succeq F\left(y_{0}, x_{0}\right) .
$$

Suppose that there exist $\phi \in \Phi$ and $\psi \in \Psi$ such that

$$
\begin{aligned}
\phi(d(F(x, y), F(u, v))) \leq & \frac{1}{2} \phi(d(G(x, y), G(u, v))+d(G(y, x), G(v, u))) \\
& -\psi\left(\frac{d(G(x, y), G(u, v))+d(G(y, x), G(v, u))}{2}\right)
\end{aligned}
$$

O2014 Erhan et al.; licensee Springer. This is an Open Access article distributed under the terms of the Creative Commons Attribution License (http://creativecommons.org/licenses/by/2.0), which permits unrestricted use, distribution, and reproduction in any medium, provided the original work is properly cited. 
for all $x, y, u, v \in X$ with $G(x, y) \preceq G(u, v)$ and $G(y, x) \succeq G(v, u)$. Suppose that for any $x, y \in X$, there exist $u, v \in X$ such that

$$
F(x, y)=G(u, v) \text { and } F(y, x)=G(v, u) .
$$

\section{Also suppose that either}

(a) $F$ is continuous, or

(b) $X$ has the following property:

(i) if a $\preceq$-non-decreasing sequence $\left\{x_{n}\right\} \rightarrow x$, then $x_{n} \preceq x$ for all $n \in \mathbb{N}$,

(ii) if a -non-increasing sequence $\left\{y_{n}\right\} \rightarrow y$, then $y \preceq y_{n}$ for all $n \in \mathbb{N}$.

Then $F$ and $G$ have a coupled coincidence point in $X$.

In this paper we show that the previous result can be easily improved because of the following facts.

(1) The mixed monotone property is not necessary since $F$ is $G$-increasing with respect to $\preceq$.

(2) It is possible to consider a pair of mappings satisfying a weaker condition than the generalized compatible property (using monotone sequences).

(3) In fact, Theorem 1.1 is not a true advance because it can be reduced to its corresponding unidimensional coincidence point theorem.

To prove our main claims, we will show a unidimensional proof of the mentioned theorem.

\section{Preliminaries}

Firstly, we recall some basic definitions and elementary results needed throughout the paper. Some of them can be found in [17]. In the sequel, we denote by $X$ a nonempty set. Given a natural number $n \in \mathbb{N}$, let $X^{n}$ be the $n$th Cartesian product $X \times X \times \cdots \times X$ ( $n$ times). We employ mappings $T, g: X \rightarrow X$ and $F: X^{n} \rightarrow X$. For simplicity, if $x \in X$, we denote $T(x)$ by $T x$.

Definition 2.1 (Khan et al. [18]) An altering distance function is a continuous, nondecreasing function $\phi:[0, \infty) \rightarrow[0, \infty)$ such that $\phi(t)=0$ if and only if $t=0$. Let $\mathcal{F}_{\text {alt }}$ denote the family of all altering distance functions.

A function $\phi:[0, \infty) \rightarrow[0, \infty)$ is said to be subadditive if $\phi(t+s) \leq \phi(t)+\phi(s)$ for all $t, s \geq 0$. Following [16], we introduce the following families of control functions. Let $\Phi$ denote the family of all subadditive altering distance functions, that is, functions $\phi:[0, \infty) \rightarrow$ $[0, \infty)$ which satisfy the following:

$\left(\phi_{1}\right) \phi$ is continuous and non-decreasing;

$\left(\phi_{2}\right) \phi(t)=0$ if and only if $t=0$;

$\left(\phi_{3}\right) \phi(t+s) \leq \phi(t)+\phi(s)$ for all $t, s \in[0, \infty)$.

We denote by $\Psi$ the family of all functions $\psi:[0, \infty) \rightarrow[0, \infty)$ which satisfy the following:

(1) $\lim _{t \rightarrow r} \psi(t)>0$ for all $r>0$;

(2) $\lim _{t \rightarrow 0^{+}} \psi(t)=0$. 
Remark 2.1 Let $\psi \in \Psi, c>0$ and define $\psi_{c}:[0, \infty) \rightarrow[0, \infty)$ by $\psi_{c}(t)=c \psi(t / c)$ for all $t \geq 0$. Then $\psi_{c} \in \Psi$.

Definition 2.2 (see $[19,20]$ ) A coincidence point of two mappings $T, g: X \rightarrow X$ is a point $x \in X$ such that $T x=g x$.

Definition 2.3 (Hussain et al. [16], Definition 10) A coupled coincidence point of two mappings $F, G: X^{2} \rightarrow X$ is a point $(x, y) \in X$ such that

$$
F(x, y)=G(x, y) \quad \text { and } \quad F(y, x)=G(y, x) .
$$

Definition 2.4 An ordered metric space $(X, d, \preceq)$ is a metric space $(X, d)$ provided with a partial order $\preceq$.

Definition $2.5([16,21])$ An ordered metric space $(X, d, \preceq)$ is said to be non-decreasingregular (respectively, non-increasing-regular) if for every sequence $\left\{x_{m}\right\} \subseteq X$ such that $\left\{x_{m}\right\} \rightarrow x$ and $x_{m} \preceq x_{m+1}$ (respectively, $x_{m} \succeq x_{m+1}$ ) for all $m$, we have that $x_{m} \preceq x$ (respectively, $\left.x_{m} \succeq x\right)$ for all $m$. $(X, d, \preceq)$ is said to be regular if it is both non-decreasing-regular and non-increasing-regular.

Remark 2.2 Notice that condition (b) in Theorem 1.1 means that $(X, d, \preceq)$ is regular.

Definition 2.6 Let $(X, \preceq)$ be a partially ordered set, and let $T, g: X \rightarrow X$ be two mappings. We say that $T$ is $(g, \preceq)$-non-decreasing if $T x \preceq T y$ for all $x, y \in X$ such that $g x \preceq g y$. If $g$ is the identity mapping on $X$, we say that $T$ is $\preceq$-non-decreasing.

Remark 2.3 If $T$ is $(g, \preceq)$-non-decreasing and $g x=g y$, then $T x=T y$. It follows that

$$
g x=g y \Rightarrow\left\{\begin{array}{l}
g x \preceq g y \\
g y \preceq g x
\end{array}\right\} \Rightarrow\left\{\begin{array}{l}
T x \preceq T y \\
T y \preceq T x
\end{array}\right\} \Rightarrow T x=T y .
$$

Definition 2.7 (Hussain et al. [16], Definition 7) Suppose that $F, G: X \times X \rightarrow X$ are two mappings, and let $\preceq$ be a partial order on $X$. The mapping $F$ is said to be G-increasing with respect to $\preceq$ if for all $x, y, u, v \in X$ with $G(x, y) \preceq G(u, v)$ we have $F(x, y) \preceq F(u, v)$.

Lemma 2.1 (see [22]) Let $(X, d)$ be a metric space and define $\Delta_{n}: X^{n} \times X^{n} \rightarrow[0, \infty)$, for all $A=\left(a_{1}, a_{2}, \ldots, a_{n}\right), B=\left(b_{1}, b_{2}, \ldots, b_{n}\right) \in X^{n}$, by

$$
\Delta_{n}(A, B)=\sum_{i=1}^{n} d\left(a_{i}, b_{i}\right)
$$

Then $\Delta_{n}$ is metric on $X^{n}$ and $(X, d)$ is complete if and only if $\left(X, \Delta_{n}\right)$ is complete.

Consider on the product space $X^{2}$ the following partial order: for $(x, y),(u, v) \in X^{2}$,

$$
(x, y) \sqsubseteq(u, v) \quad \Leftrightarrow \quad[x \preceq u \text { and } y \succeq v] .
$$


Definition $2.8([17,23-25])$ Let $(X, d, \preceq)$ be an ordered metric space. Two mappings $T, g$ : $X \rightarrow X$ are said to be $O$-compatible if

$$
\lim _{m \rightarrow \infty} d\left(g \operatorname{Tx}, \operatorname{Tg} x_{m}\right)=0
$$

provided that $\left\{x_{m}\right\}$ is a sequence in $X$ such that $\left\{g x_{m}\right\}$ is $\preceq$-monotone, that is, it is either non-increasing or non-decreasing with respect to $\preceq$, and

$$
\lim _{m \rightarrow \infty} T x_{m}=\lim _{m \rightarrow \infty} g x_{m} \in X
$$

Definition 2.9 (Hussain et al. [16], Definition 12) Let $F, G: X \times X \rightarrow X$. We say that the pair $\{F, G\}$ is generalized compatible if for all sequences $\left\{x_{n}\right\},\left\{y_{n}\right\} \subseteq X$ such that

$$
\lim _{n \rightarrow \infty} F\left(x_{n}, y_{n}\right)=\lim _{n \rightarrow \infty} G\left(x_{n}, y_{n}\right)=t_{1} \in X \quad \text { and } \quad \lim _{n \rightarrow \infty} F\left(y_{n}, x_{n}\right)=\lim _{n \rightarrow \infty} G\left(y_{n}, x_{n}\right)=t_{2} \in X,
$$

we have that

$$
\begin{aligned}
& \lim _{n \rightarrow \infty} d\left(F\left(G\left(x_{n}, y_{n}\right), G\left(y_{n}, x_{n}\right)\right), G\left(F\left(x_{n}, y_{n}\right), F\left(y_{n}, x_{n}\right)\right)\right)=0 \quad \text { and } \\
& \lim _{n \rightarrow \infty} d\left(F\left(G\left(y_{n}, x_{n}\right), G\left(x_{n}, y_{n}\right)\right), G\left(F\left(y_{n}, x_{n}\right), F\left(x_{n}, y_{n}\right)\right)\right)=0 .
\end{aligned}
$$

\section{Main results}

To start with, we highlight the weakness of Theorem 1.1 using the following example.

Example 3.1 Let $X=[0, \infty)$ endowed with the standard metric $d(x, y)=|x-y|$ for all $x, y \in X$. Consider the maps $F, G: X \times X \rightarrow X$ defined by

$$
F(x, y)=\frac{3}{5} x-\frac{1}{5} y \quad \text { and } \quad G(x, y)=\frac{x-y}{2} \quad \text { for all } x, y \in X .
$$

Then, for all $x, y, u, v \in X$ with $y=v$, we have

$$
d(F(x, y), F(u, v))=\frac{3}{5}|x-u| \quad \text { and } \quad d(G(x, y), G(u, v))+d(G(y, x), G(v, u))=|x-u| .
$$

Thus,

$$
d(F(x, y), F(u, v))>\frac{1}{2}(d(G(x, y), G(u, v))+d(G(y, x), G(v, u))) .
$$

Regarding the properties of the functions in $\Phi$, we derive that

$$
\varphi(d(F(x, y), F(u, v)))>\frac{1}{2} \varphi(d(G(x, y), G(u, v))+d(G(y, x), G(v, u))) .
$$

Since the function in the class $\Psi$ takes values on $[0, \infty)$, it is impossible to verify inequality (2). Hence, Theorem 1.1 cannot be applied to get a coupled coincidence point. However, it is easy to see that $(0,0)$ is a coupled coincidence point of $F$ and $G$. 
Next, we show a unidimensional version of Theorem 1.1. Notice that, indeed, the following result is better than Theorem 1.1 because we reorder the hypotheses obtaining that, in some cases, neither the continuity of, at least, one mapping ( $T$ or $g$ ) nor the $O$ compatibility of the pair $(T, g)$ is necessary. In fact, both hypotheses are omitted in case (c).

Theorem 3.1 Let $(X, d, \preceq)$ be an ordered metric space, and let $T, g: X \rightarrow X$ be two mappings such that the following properties are fulfilled:

(i) $T(X) \subseteq g(X)$;

(ii) $T$ is $(g, \preceq)$-non-decreasing;

(iii) there exists $x_{0} \in X$ such that $g x_{0} \preceq T x_{0}$;

(iv) there exist $\phi \in \Phi$ and $\psi \in \Psi$ verifying

$$
\phi(d(T x, T y)) \leq \phi(d(g x, g y))-\psi(d(g x, g y)) \quad \text { for all } x, y \in X \text { such that } g x \preceq g y .
$$

Also assume that, at least, one of the following conditions holds.

(a) $(X, d)$ is complete, $T$ and $g$ are continuous and the pair $(T, g)$ is O-compatible;

(b) $(X, d)$ is complete and $T$ and $g$ are continuous and commuting;

(c) $(g(X), d)$ is complete and $(X, d, \preceq)$ is non-decreasing-regular;

(d) $(X, d)$ is complete, $g(X)$ is closed and $(X, d, \preceq)$ is non-decreasing-regular;

(e) $(X, d)$ is complete, $g$ is continuous and monotone $\preceq$-non-decreasing, the pair $(T, g)$ is O-compatible and $(X, d, \preceq)$ is non-decreasing-regular.

Then $T$ and $g$ have, at least, a coincidence point.

We omit the proof of the previous result since its proof is similar to the main theorem in [17] and it can be concluded by following, point by point, all of its arguments.

Next, we show how to deduce an appropriate version of Theorem 1.1 from Theorem 3.1. Given the ordered metric space $(X, d, \preceq)$, let us consider the ordered metric space $\left(X^{2}, \Delta_{2}\right.$, $)$, where $\Delta_{2}$ was defined in Lemma 2.1 and $\sqsubseteq$ was introduced in (4). We define the mappings $T_{F}, T_{G}: X^{2} \rightarrow X^{2}$, for all $(x, y) \in X^{2}$, by

$$
T_{F}(x, y)=(F(x, y), F(y, x)) \text { and } \quad T_{G}(x, y)=(G(x, y), G(y, x)) .
$$

Under these conditions, the following properties hold.

Lemma 3.1 Let $(X, d, \preceq)$ be an ordered metric space, and let $F, G: X^{2} \rightarrow X$ be two mappings. Then the following properties hold.

(1) $(X, d)$ is complete if and only if $\left(X^{2}, \Delta_{2}\right)$ is complete.

(2) If $(X, d, \preceq)$ is regular, then $\left(X^{2}, \Delta_{2}\right.$, $\left.匚\right)$ is also regular.

(3) If $F$ is $d$-continuous, then $T_{F}$ is $\Delta_{2}$-continuous.

(4) If $F$ is $G$-increasing with respect to $\preceq$, then $T_{F}$ is $\left(T_{G}\right.$, 5$)$-non-decreasing.

(5) Condition (1) is equivalent to the existence of a point $\left(x_{0}, y_{0}\right) \in X^{2}$ such that $T_{G}\left(x_{0}, y_{0}\right) \sqsubseteq T_{F}\left(x_{0}, y_{0}\right)$.

(6) Condition (3) is equivalent to $T_{F}\left(X^{2}\right) \subseteq T_{G}\left(X^{2}\right)$.

(7) If there exist $\phi \in \Phi$ and $\psi \in \Psi$ such that (2) holds, then

$$
\phi\left(\Delta_{2}\left(T_{F}(x, y), T_{F}(u, v)\right)\right) \leq \phi\left(\Delta_{2}\left(T_{G}(x, y), T_{G}(u, v)\right)\right)-\psi_{2}\left(\Delta_{2}\left(T_{G}(x, y), T_{G}(u, v)\right)\right)
$$


for all $(x, y),(u, v) \in X^{2}$ such that $T_{G}(x, y) \sqsubseteq T_{G}(u, v)$, where $\psi_{2} \in \Psi$ was defined in Remark 2.1.

(8) If the pair $\{F, G\}$ is generalized compatible, then the mappings $T_{F}$ and $T_{G}$ are O-compatible in $\left(X^{2}, \Delta_{2}, \sqsubseteq\right)$.

(9) A point $(x, y) \in X^{2}$ is a coupled coincidence point of $F$ and $G$ if and only if it is a coincidence point of $T_{F}$ and $T_{G}$.

Proof Item (1) follows from Lemma 2.1 and items (2), (3), (5), (6) and (9) are obvious.

(4) Assume that $F$ is $G$-increasing with respect to $\preceq$, and let $(x, y),(u, v) \in X^{2}$ be such that $T_{G}(x, y) \sqsubseteq T_{G}(u, v)$. Then $G(x, y) \preceq G(u, v)$ and $G(y, x) \succeq G(v, u)$. Since $F$ is $G$ increasing with respect to $\preceq$, we deduce that $F(x, y) \preceq F(u, v)$ and $F(y, x) \succeq F(v, u)$. Therefore, $T_{F}(x, y) \sqsubseteq T_{F}(u, v)$ and this means that $T_{F}$ is $\left(T_{G}, \sqsubseteq\right)$-non-decreasing.

(7) Suppose that there exist $\phi \in \Phi$ and $\psi \in \Psi$ such that (2) holds, and let $(x, y),(u, v) \in X^{2}$ be such that $T_{G}(x, y) \sqsubseteq T_{G}(u, v)$. Therefore $G(x, y) \preceq G(u, v)$ and $G(y, x) \succeq G(v, u)$. Using $(2)$, we have that

$$
\begin{aligned}
\phi(d(F(x, y), F(u, v))) \leq & \frac{1}{2} \phi(d(G(x, y), G(u, v))+d(G(y, x), G(v, u))) \\
& -\psi\left(\frac{d(G(x, y), G(u, v))+d(G(y, x), G(v, u))}{2}\right) .
\end{aligned}
$$

Furthermore, taking into account that $G(v, u) \preceq G(y, x)$ and $G(u, v) \succeq G(x, y)$, the contractivity condition (2) also guarantees that

$$
\begin{aligned}
\phi(d(F(v, u), F(y, x))) \leq & \frac{1}{2} \phi(d(G(v, u), G(y, x))+d(G(u, v), G(x, y))) \\
& -\psi\left(\frac{d(G(v, u), G(y, x))+d(G(u, v), G(x, y))}{2}\right) .
\end{aligned}
$$

Since $\phi$ is subadditive, it follows from (5) and (6) that

$$
\begin{aligned}
\phi( & \left.\Delta_{2}\left(T_{F}(x, y), T_{F}(u, v)\right)\right) \\
= & \phi\left(\Delta_{2}[(F(x, y), F(y, x)),(F(u, v), F(v, u))]\right) \\
= & \phi(d(F(x, y), F(u, v))+d(F(y, x), F(v, u))) \\
\leq & \phi(d(F(x, y), F(u, v)))+\phi(d(F(y, x), F(v, u))) \\
\leq & \phi(d(G(x, y), G(u, v))+d(G(y, x), G(v, u))) \\
& -2 \psi\left(\frac{d(G(v, u), G(y, x))+d(G(u, v), G(x, y))}{2}\right) \\
= & \phi\left(\Delta_{2}\left(T_{G}(x, y), T_{G}(u, v)\right)\right)-\psi_{2}\left(\Delta_{2}\left(T_{G}(x, y), T_{G}(u, v)\right)\right) .
\end{aligned}
$$

(8) Let $\left\{\left(x_{m}, y_{m}\right)\right\} \subseteq X^{2}$ be any sequence such that $\left\{T_{F}\left(x_{m}, y_{m}\right)\right\} \stackrel{\Delta_{2}}{\longrightarrow}(x, y)$ and $\left\{T_{G}\left(x_{m}, y_{m}\right)\right\} \stackrel{\Delta_{2}}{\longrightarrow}(x, y)$ (notice that we do not need to suppose that $\left\{T_{G}\left(x_{m}, y_{m}\right)\right\}$ is $\sqsubseteq$ monotone). Therefore,

$$
\left\{\left(F\left(x_{m}, y_{m}\right), F\left(y_{m}, x_{m}\right)\right)\right\} \stackrel{\Delta_{2}}{\longrightarrow}(x, y) \Rightarrow\left[\left\{F\left(x_{m}, y_{m}\right)\right\} \stackrel{d}{\longrightarrow} x \text { and }\left\{F\left(y_{m}, x_{m}\right)\right\} \stackrel{d}{\longrightarrow} y\right] ;
$$




$$
\begin{aligned}
& \left\{\left(G\left(x_{m}, y_{m}\right), G\left(y_{m}, x_{m}\right)\right)\right\} \stackrel{\Delta_{2}}{\longrightarrow}(x, y) \\
& \quad \Rightarrow \quad\left[\left\{G\left(x_{m}, y_{m}\right)\right\} \stackrel{d}{\longrightarrow} x \text { and }\left\{G\left(y_{m}, x_{m}\right)\right\} \stackrel{d}{\rightarrow} y\right] .
\end{aligned}
$$

Therefore

$$
\begin{aligned}
& \lim _{m \rightarrow \infty} F\left(x_{m}, y_{m}\right)=\lim _{m \rightarrow \infty} G\left(x_{m}, y_{m}\right)=x \in X \quad \text { and } \\
& \lim _{m \rightarrow \infty} F\left(y_{m}, x_{m}\right)=\lim _{m \rightarrow \infty} G\left(y_{m}, x_{m}\right)=y \in X .
\end{aligned}
$$

Since the pair $\{F, G\}$ is generalized compatible, we deduce that

$$
\begin{aligned}
& \lim _{m \rightarrow \infty} d\left(F\left(G\left(x_{m}, y_{m}\right), G\left(y_{m}, x_{m}\right)\right), G\left(F\left(x_{m}, y_{m}\right), F\left(y_{m}, x_{m}\right)\right)\right)=0 \quad \text { and } \\
& \lim _{m \rightarrow \infty} d\left(F\left(G\left(y_{m}, x_{m}\right), G\left(x_{m}, y_{m}\right)\right), G\left(F\left(y_{m}, x_{m}\right), F\left(x_{m}, y_{m}\right)\right)\right)=0 .
\end{aligned}
$$

In particular,

$$
\begin{aligned}
\lim _{m \rightarrow \infty} & \Delta_{2}\left(T_{G} T_{F}\left(x_{m}, y_{m}\right), T_{F} T_{G}\left(x_{m}, y_{m}\right)\right) \\
= & \lim _{m \rightarrow \infty} \Delta_{2}\left(T_{G}\left(F\left(x_{m}, y_{m}\right), F\left(y_{m}, x_{m}\right)\right), T_{F}\left(G\left(x_{m}, y_{m}\right), G\left(y_{m}, x_{m}\right)\right)\right) \\
= & \lim _{m \rightarrow \infty} \Delta_{2}\left(\left(G\left(F\left(x_{m}, y_{m}\right), F\left(y_{m}, x_{m}\right)\right), G\left(F\left(y_{m}, x_{m}\right), F\left(x_{m}, y_{m}\right)\right)\right),\right. \\
& \left.\left(F\left(G\left(x_{m}, y_{m}\right), G\left(y_{m}, x_{m}\right)\right), F\left(G\left(y_{m}, x_{m}\right), G\left(x_{m}, y_{m}\right)\right)\right)\right) \\
= & \lim _{m \rightarrow \infty}\left[d\left(\left(G\left(F\left(x_{m}, y_{m}\right), F\left(y_{m}, x_{m}\right)\right), F\left(G\left(x_{m}, y_{m}\right), G\left(y_{m}, x_{m}\right)\right)\right)\right)\right. \\
& \left.+d\left(\left(G\left(F\left(y_{m}, x_{m}\right), F\left(x_{m}, y_{m}\right)\right), F\left(G\left(y_{m}, x_{m}\right), G\left(x_{m}, y_{m}\right)\right)\right)\right)\right] \\
= & 0 .
\end{aligned}
$$

Hence, the mappings $T_{F}$ and $T_{G}$ are $O$-compatible in $\left(X^{2}, \Delta_{2}, \sqsubseteq\right)$.

As a consequence, we conclude that Hussain $e t$ al.'s result can be deduced from the corresponding unidimensional result. Furthermore, as we have pointed out, it is not necessary for $G$ to have the mixed monotone property because $F$ is $G$-increasing with respect to $\preceq$.

Corollary 3.1 Theorem 1.1, even avoiding the assumption that $G$ has the mixed monotone property, is a consequence of Theorem 3.1.

Proof It is only necessary to apply Theorem 3.1 to the mappings $T=T_{F}$ and $g=T_{G}$ in the ordered metric space $\left(X^{2}, \Delta_{2}\right.$, ㄷ), taking into account all items of Lemma 3.1.

The following result is an improved version of Theorem 1.1 in which the contractivity condition is replaced by a more convenient one, which is symmetric on the variables $(x, y)$ and $(u, v)$.

Corollary 3.2 Let $(X, \preceq)$ be a partially ordered set such that there exists a complete metric $d$ on $X$. Assume that $F, G: X \times X \rightarrow X$ are two generalized compatible mappings such that 
$F$ is $G$-increasing with respect to $\preceq, G$ is continuous and there exist two elements $x_{0}, y_{0} \in X$ such that

$$
G\left(x_{0}, y_{0}\right) \preceq F\left(x_{0}, y_{0}\right) \quad \text { and } \quad G\left(y_{0}, x_{0}\right) \succeq F\left(y_{0}, x_{0}\right)
$$

Suppose that there exist $\phi \in \Phi$ and $\psi \in \Psi$ such that

$$
\begin{aligned}
\phi( & \left.\frac{d(F(x, y), F(u, v))+d(F(y, x), F(v, u))}{2}\right) \\
\leq & \phi\left(\frac{d(G(x, y), G(u, v))+d(G(y, x)+G(v, u))}{2}\right) \\
& -\psi\left(\frac{d(G(x, y), G(u, v))+d(G(y, x)+G(v, u))}{2}\right)
\end{aligned}
$$

for all $x, y, u, v \in X$ with $G(x, y) \preceq G(u, v)$ and $G(y, x) \succeq G(v, u)$. Suppose that for any $x, y \in X$, there exist $u, v \in X$ such that

$$
F(x, y)=G(u, v) \quad \text { and } \quad G(y, x) \succeq F(y, x) .
$$

\section{Also assume that either}

(a) $F$ is continuous, or

(b) $(X, d, \preceq)$ is regular.

Then $F$ and $G$ have, at least, a coupled coincidence point, that is, there exist $x, y \in X$ such that $G(x, y)=F(x, y)$ and $G(y, x)=F(y, x)$.

Proof It is only necessary to apply Theorem 3.1 to the mappings $T=T_{F}$ and $g=T_{G}$ in the ordered metric space $\left(X^{2}, \Delta_{2}^{\prime}\right.$, ᄃ), where $\Delta_{2}^{\prime}=\Delta_{2} / 2$, taking into account all items of Lemma 3.1.

In the following example we show that Corollary 3.2 is applicable to the mappings of Example 3.1, when Theorem 1.1 is not useful.

Example 3.2 Let $X=[0, \infty)$ endowed with the Euclidean metric $d(x, y)=|x-y|$ for all $x, y \in X$. Consider the maps $F, G: X \times X \rightarrow X$ defined by

$$
F(x, y)=\frac{3}{5} x-\frac{1}{5} y \quad \text { and } \quad G(x, y)=\frac{x-y}{2} \quad \text { for all } x, y \in X .
$$

Then, for all $x, y, u, v \in X$ with $y=v$, we have

$$
\begin{aligned}
& d(F(x, y), F(u, v))+d(F(y, x), F(v, u))=\frac{4}{5}(|x-u|+|y-v|) \quad \text { and } \\
& d(G(x, y), G(u, v))+d(G(y, x), G(v, u))=|x-u|+|y-v| .
\end{aligned}
$$

Thus,

$$
d(F(x, y), F(u, v))<d(G(x, y), G(u, v))+d(G(y, x), G(v, u)) .
$$


Regarding the properties of the functions in $\Phi$, we derive that

$$
\begin{aligned}
\phi( & \left.\frac{d(F(x, y), F(u, v))+d(F(y, x), F(v, u))}{2}\right) \\
& \leq \phi\left(\frac{d(G(x, y), G(u, v))+d(G(y, x)+G(v, u))}{2}\right) .
\end{aligned}
$$

To provide inequality (7), it is sufficient to choose $\psi(t)=\frac{t}{10}$. Hence, Theorem 3.2 can be applied in order to guarantee that $F$ and $G$ have a coupled coincidence point. Indeed, it is easy to check that $(0,0)$ is a coupled coincidence point of $F$ and $G$.

To finish the paper, we want to point out a pair of details.

(1) The function in $\phi$ in Theorem 3.1 is not a true generalization because if $\phi \in \Phi$, then the mapping $d_{\phi}: X \times X \rightarrow[0, \infty)$, defined by $d_{\phi}(x, y)=\phi(d(x, y))$ for all $x, y \in X$, is also a metric on $X$. For more details, see [26]. Notice also that the assumption of sub-additivity $\left(\phi_{2}\right)$ is superfluous in most of the published results (see, e.g., [27]).

(2) Using the same techniques that can be found in [17, 22, 28-31], it is possible to deduce, from Theorem 3.1, tripled, quadrupled and, in general, multidimensional coincidence point theorems.

\section{Competing interests}

The authors declare that they have no competing interests.

\section{Authors' contributions}

All authors contributed equally and significantly in writing this article. All authors read and approved the final manuscript.

\section{Author details}

${ }^{1}$ Department of Mathematics, Atilim University, Incek, Ankara, 06836, Turkey. ${ }^{2}$ Nonlinear Analysis and Applied Mathematics Research Group (NAAM), King Abdulaziz University, Jeddah, 21589, Saudi Arabia. ${ }^{3}$ Department of Mathematics, University of Jaén, Campus las Lagunillas s/n, Jaén, 23071, Spain. ${ }^{4}$ Department of Mathematics, King Abdulaziz University, P.O. Box 80203, Jeddah, 21589, Saudi Arabia.

\section{Acknowledgements}

This article was funded by the Deanship of Scientific Research (DSR), King Abdulaziz University, Jeddah. N Shahzad acknowledges with thanks DSR for financial support. Antonio Roldán has been partially supported by Junta de Andalucía by project FQM-268 of the Andalusian CICYE.

\section{Received: 19 May 2014 Accepted: 6 August 2014 Published: 13 Oct 2014}

\section{References}

1. Luong, NV, Thuan, NX: Coupled fixed points in partially ordered metric spaces and application. Nonlinear Anal. 74 983-992 (2011)

2. Abbas, M, Rhoades, BE: Common fixed point results for noncommuting mappings without continuity in generalized metric spaces. Appl. Math. Comput. 215, 262-269 (2009)

3. Haghi, RH, Rezapour, S, Shahzad, N: Some fixed point generalizations are not real generalizations. Nonlinear Anal. 74, 1799-1803 (2011)

4. Berinde, $\mathrm{V}$ : Coupled fixed point theorems for $\phi$-contractive mixed monotone mappings in partially ordered metric spaces. Nonlinear Anal. 75, 3218-3228 (2012)

5. Bilgili, $\mathrm{N}$, Karapınar, E, Turkoglu, D: A note on common fixed points for $(\psi, \alpha, \beta)$-weakly contractive mappings in generalized metric spaces. Fixed Point Theory Appl. 2013, Article ID 287 (2013)

6. Harjani, J, Sadarangani, K: Generalized contractions in partially ordered metric spaces and applications to ordinary differential equations. Nonlinear Anal. 72, 1188-1197 (2010)

7. Turkoglu, D, Sangurlu, M: Coupled fixed point theorems for mixed $g$-monotone mappings in partially ordered metric spaces. Fixed Point Theory Appl. 2013, Article ID 348 (2013)

8. Roldán, A, Martínez-Moreno, J, Roldán, C: Multidimensional fixed point theorems in partially ordered complete metric spaces. J. Math. Anal. Appl. 396(2), 536-545 (2012)

9. Roldán, A, Martínez-Moreno, J, Roldán, C, Karapınar, E: Multidimensional fixed point theorems in partially ordered complete partial metric spaces under $(\psi, \varphi)$-contractivity conditions. Abstr. Appl. Anal. 2013, Article ID 634371 (2013)

10. Karapınar, E, Roldán, A, Martínez-Moreno, J, Roldán, C: Meir-Keeler type multidimensional fixed point theorems in partially ordered metric spaces. Abstr. Appl. Anal. 2013, Article ID 406026 (2013) 
11. Pathak, HK, Shahzad, N: Fixed point results for set-valued contractions by altering distances in complete metric spaces. Nonlinear Anal. 70(7), 2634-2641 (2009)

12. Alshehri, S, Aranđelović, I, Shahzad, N: Symmetric spaces and fixed points of generalized contractions. Abstr. Appl. Anal. 2014, Article ID 763547 (2014)

13. Asl, JH, Rezapour, S, Shahzad, N: On fixed points of $\alpha$ - $\psi$-contractive multifunctions. Fixed Point Theory Appl. 2012, Article ID 212 (2012). doi:10.1186/1687-1812-2012-212

14. Mohammadi, B, Rezapour, S, Shahzad, N: Some results on fixed points of $\alpha$ - $\psi$-Ćirić generalized multifunctions. Fixed Point Theory Appl. 2013, Article ID 24 (2013). doi:10.1186/1687-1812-2013-24

15. Alikhani, H, Rezapour, S, Shahzad, N: Fixed points of a new type contractive mappings and multifunctions. Filomat 27(7), 1315-1319 (2013)

16. Hussain, N, Abbas, M, Azam, A, Ahmad, J: Coupled coincidence point results for a generalized compatible pair with applications. Fixed Point Theory Appl. 2014, Article ID 62 (2014)

17. Al-Mezel, SA, Alsulami, H, Karapınar, E, Roldán, A: Discussion on 'Multidimensional coincidence points' via recent publications. Abstr. Appl. Anal. 2014, Article ID 287492 (2014) http://www.hindawi.com/journals/aaa/aip/287492/

18. Khan, MS, Swaleh, M, Sessa, S: Fixed point theorems by altering distances between the points. Bull. Aust. Math. Soc. 30, 1-9 (1984)

19. Goebel, K: A coincidence theorem. Bull. Acad. Pol. Sci., Sér. Sci. Math. Astron. Phys. 16, 733-735 (1968)

20. Agarwal, RP, Bisht, RK, Shahzad, N: A comparison of various noncommuting conditions in metric fixed point theory and their applications. Fixed Point Theory Appl. 2014, Article ID 38 (2014)

21. Bhaskar, TG, Lakshmikantham, V: Fixed point theory in partially ordered metric spaces and applications. Nonlinear Anal. 65, 1379-1393 (2006)

22. Roldán, A, Martínez-Moreno, J, Roldán, C, Karapınar, E: Some remarks on multidimensional fixed point theorems. Fixed Point Theory Appl. 2013, Article ID 158 (2013)

23. Choudhury, BS, Kundu, A: A coupled coincidence point result in partially ordered metric spaces for compatible mappings. Nonlinear Anal. 73, 2524-2531 (2010)

24. Luong, NV, Thuan, NX: Coupled points in ordered generalized metric spaces and application to integro-differential equations. Comput. Math. Appl. 62(11), 4238-4248 (2011)

25. Hung, NM, Karapınar, E, Luong, NV: Coupled coincidence point theorem for O-compatible mappings via implicit relation. Abstr. Appl. Anal. 2012, Article ID 796964 (2012)

26. Karapınar, E, Samet, B: A note on $\psi$-Geraghty contractions. Fixed Point Theory Appl. 2014, Article ID 26 (2014)

27. Karapınar, E: A discussion on $\alpha-\psi$ Geraghty contracton type mappings and some related fixed point results. Filomat 28(1), 37-48 (2014)

28. Karapınar, E, Roldán, A: A note on ' $n$-Tuplet fixed point theorems for contractive type mappings in partially ordered metric spaces'. J. Inequal. Appl. 2013, Article ID 567 (2013)

29. Karapınar, E, Roldán, A, Roldán, C, Martínez-Moreno, J: A note on 'N-Fixed point theorems for nonlinear contractions in partially ordered metric spaces'. Fixed Point Theory Appl. 2013, Article ID 310 (2013)

30. Karapınar, E, Roldán, A, Shahzad, N, Sintunavarat, W: Discussion on coupled and tripled coincidence point theorems for $\phi$-contractive mappings without the mixed $g$-monotone property. Fixed Point Theory Appl. 2014, Article ID 92 (2014)

31. Samet, B, Karapınar, E, Aydi, H, Rajic, VC: Discussion on some coupled fixed point theorems. Fixed Point Theory Appl. 2013, Article ID 50 (2013)

10.1186/1687-1812-2014-207

Cite this article as: Erhan et al.: Remarks on 'Coupled coincidence point results for a generalized compatible pair with applications'. Fixed Point Theory and Applications 2014, 2014:207

\section{Submit your manuscript to a SpringerOpen ${ }^{\odot}$ journal and benefit from:}

- Convenient online submission

- Rigorous peer review

Immediate publication on acceptance

- Open access: articles freely available online

- High visibility within the field

- Retaining the copyright to your article 